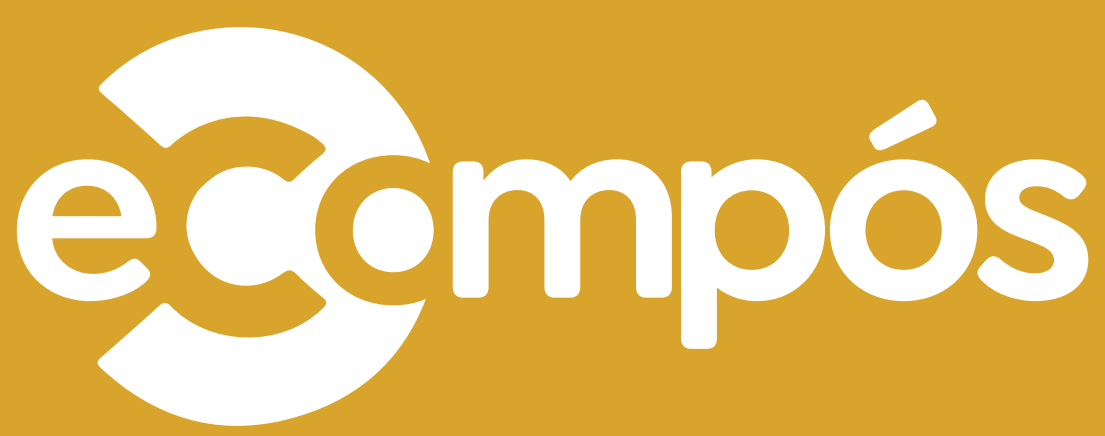

Revista da Associação Nacional dos Programas de Pós-Graduação em Comunicação

ISSN 1808-2599, v. 24, jan-dez, publicação contínua, 2021, p. 1-21.

doi.org/10.30962/ec.2229

\title{
Vínculos sonoros na diáspora Investigando a teia de afetos entre migrantes e o rádio expandido
}

\section{BÁRBARA MAIA}

Universidade do Estado do Rio de Janeiro, Rio de Janeiro, Brasil

\section{MARCELO KISCHINHEVSKY}

Universidade Federal do Rio de Janeiro, Rio de Janeiro, Brasil

\section{BELÉN MONCLÚS}

Universitat Autònoma de Barcelona, Espanha

\section{ID 2229}

Recebido em

03/07/2020

Aceito em

21/09/2020 


\section{/ resumo}

O artigo investiga os vínculos afetivos construídos através da escuta radiofônica por brasileiros em condição de diáspora. Parte-se do conceito de rádio expandido e da sociologia do afeto para se discutir em que medida essa audiência diaspórica constrói sentido para a escuta, num processo de afirmação identitária, de (re)conexão com a língua pátria e também de negociação para se inserir numa outra cultura. 0 percurso da pesquisa inclui análise qualitativa de 20 entrevistas semiestruturadas feitas com brasileiros que vivem em Barcelona, buscando compreender como constroem sentido para a comunicação sonora e em que medida o rádio expandido oferece um entre-lugar para o migrante.

Palavras-chave: Rádio. Vínculo. Som. Identidade. Diáspora.

\section{Enlaces sonoros en la diáspora: investigar la red de afectos entre los migrantes y la radio expandida}

El artículo investiga los lazos afectivos construidos a través de la radio que escuchan los brasileños en condiciones de diáspora. Se inicia con el concepto de radio expandida y la sociología del afecto para discutir en qué medida esta audiencia diaspórica construye significado para escuchar, en un proceso de afirmación de identidad, de (re) conexión con la lengua materna y también de negociación para insertar en otra cultura. La ruta de investigación incluye un análisis cualitativo de 20 entrevistas semiestructuradas con brasileños que viven en Barcelona, buscando comprender cómo tienen sentido para la comunicación sonora y hasta qué punto la radio expandida ofrece un lugar para los migrantes.

Palabras clave: Radio. Enlace. Sonido. Identidad. Diáspora.
Sound bonds in diaspora: Investigating the web ofaffections between migrants and expanded radio

This paper investigates the affective bonds built through radio listening by Brazilians in diaspora conditions. It starts from the concept of expanded radio and the sociology of affection to discuss the extent to which this diasporic audience builds meaning for listening, in an identity affirmation process, of (re)connection with mother tongue and also negotiation to insert oneself in another culture. The research path includes a qualitative analysis of information gathered in 20 semistructured interviews with Brazilians living in Barcelona, seeking to understand how they build meaning for sound communication and the extent to which expanded radio offers an in between place for migrants.

Keywords: Radio. Bonds. Sound. Identity. Diaspora. 


\section{/autores}

\section{ecompós}

\section{Bárbara MAIA}

Doutora pelo Programa de Pós-Graduação em Comunicação da Universidade do Estado do Rio de Janeiro, com bolsa FAPERJ. Mestre pelo Programa de Pós-Graduação em Comunicação da Universidade Federal do Paraná, onde foi bolsista da CAPES. Realizou estágio de doutorado sanduíche na Universitàt Autònoma de Barcelona com bolsa Capes Print.

Universidade do Estado do Rio de Janeiro, Rio de Janeiro, Brasil

E-mail: barbaramaiap@gmail.com

\section{ORCID}

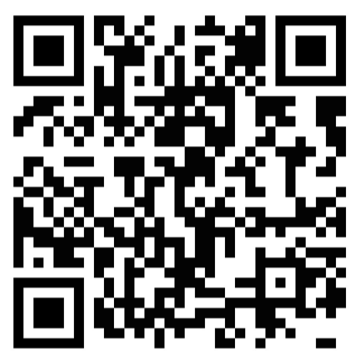

\section{Marcelo KISCHINHEVSKY}

Doutor em Comunicação e Cultura pela Escola de Comunicação da Universidade Federal do Rio de Janeiro (ECO/UFRJ). Diretor do Núcleo de Rádio e TV da Universidade Federal do Rio de Janeiro (UFRJ). Professor dos cursos de Jornalismo e de Rádio e TV da Escola de Comunicação da Universidade Federal do Rio de Janeiro e também do Programa de Pós-Graduação em Comunicação (PPGCOM), da Faculdade de Comunicação Social da Universidade do Estado do Rio de Janeiro (FCS/UERJ). Coordena os Grupos de Pesquisa (GPs) Rádio e Mídia Sonora, da Sociedade Brasileira de Estudos Interdisciplinares da Comunicação (Intercom), e Mediações e Interações Radiofônicas, listado no CNPq.

Universidade Federal do Rio de Janeiro, Rio de Janeiro, Rio de Janeiro, Brasil

E-mail: marcelokisch@gmail.com

\section{ORCID}

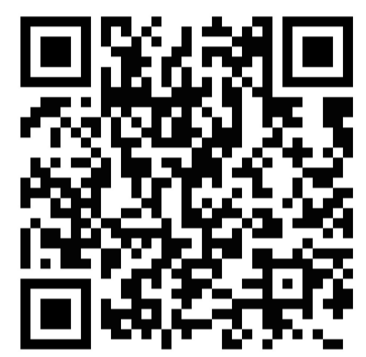




\section{/autores}

\section{ecompós}

\section{Belén \\ MONCLÚS}

Doutora em Comunicação Audiovisual

pela Universidade Autônoma de

Barcelona (UAB, Espanha). Professora

do Departamento de Comunicação e

Publicidade Audiovisual da Universidade

Autônoma de Barcelona, coordenadora

do Observatório de Rádio da Catalunha

(GRISS-UAB) e presidente da Seção de

Rádio da European Communication

Research and Education Asociation

(ECREA).

Universitat Autònoma de Barcelona,

Espanha

E-mail: belen.monclus@gmail.com

\section{ORCID}

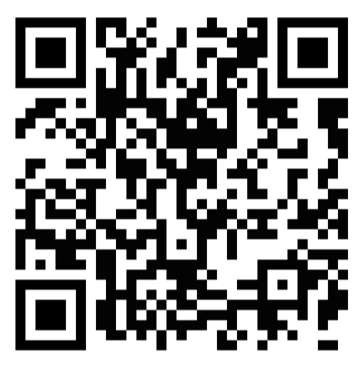




\section{Introdução}

O ônibus segue seu caminho, percorrendo as ruas de Barcelona. Entre os passageiros, um sujeito sentado, quieto, com seu fone de ouvido, está imerso numa ambiência sonora individualizada e desencaixada do entorno. Pelo telefone, sintoniza uma rádio de sua cidade natal, situada a mais de oito mil quilômetros de distância, no Brasil, mas que ainda assim the oferece uma trilha sonora para a rotina diária, que o envolve, entretém e informa, motivando-o para mais um dia de trabalho. A música e as vozes de locutores, repórteres e entrevistados alimentam vínculos e despertam afetos, ressignificando paisagens de outro lugar, uma cidade que assim se desvela estrangeira aos olhos e ouvidos do migrante.

As formas como construímos sentido para a escuta radiofônica em nossas vidas cotidianas são tão diversas quantas as perspectivas teóricas que cercam o meio. Tratado inicialmente como "oitava arte" (ARNHEIM, 1980), mas logo alvo de estudos críticos, por servir de relógio da sociedade industrial fordista (ADORNO; HORKHEIMER, 1985) ou por ser uma oportunidade perdida de estabelecer uma comunicação realmente democrática (BRECHT, 2005), o rádio se fragmenta ao longo das últimas décadas como objeto de estudos. As chaves conceituais são as mais diversas: linguagem (BALSEBRE, 2007), discurso (CHARAUDEAU, 2005; HAYE, 2005), semiótica (MORAGAS SPA, 2008; FERNÁNDEZ, 2008, 2012), retórica (KLÖCKNER, 2011), jornalismo (MEDITSCH, 2001; LOPEZ, 2010), história (FERRARETTO, 2007), tecnologia (CEBRIÁN HERREROS, 2008), regulação (BIANCO; ESCH; MOREIRA, 2015), recepção (WINOCUR, 2002; KASEKER, 2012), interações e mediações (KISCHINHEVSKY, 2017). A radiofonia constitui um espaço sonoro complexo, que contribuiu, ao longo do século XX, de forma decisiva para a construção social da cultura e da própria noção de cidadania, de imaginários, estilos de vida, negociações identitárias e de alteridade, formas de convívio, representação simbólica, modos de inclusão e exclusão social, instituições e práticas políticas, relações de poder.

Rosalía Winocur, pesquisadora argentina radicada no México, ressalta que o rádio estabeleceu um circuito inédito de intercâmbio de experiências entre ambientes públicos e privados, que passaram a se influenciar mutuamente, servindo como uma espécie de mapa de navegação pela vida urbana contemporânea:

\footnotetext{
A narrativa radiofônica evoluiu de um imaginário de inclusão da diferença para um imaginário de diversificação da experiência, no qual aqueles que são diferentes não reivindicam mais ser incluídos, mas sim reconhecidos e respeitados ${ }^{1}$ (WINOCUR, 2002, p. 197, tradução nossa).
}

A autora considera o noticiário radiofônico uma das narrativas fundamentais na criação e projeção de personagens, modelos de relação e formas de sociabilidade tipicamente urbanos, ajudando a construir a imagem da cidade e reproduzindo estereótipos e mitos, mas também gerando espaços importantes para canalização e expressão de inquietações políticas e civis. Constitui, nesse sentido, um grande receituário da modernidade, com múltiplas propostas e indicações para ser e estar na cidade.

A realidade é interpretada pelas grandes narrativas radiofônicas a partir de moldes míticos e ideológicos, que processam a diversidade, a novidade e a alteridade.

As receitas, os mitos, as crenças, os lugares comuns, a linguagem coloquial são parte de uma estrutura narrativa que pode se assemelhar à vida cotidiana, tanto na organização do tempo quanto do espaço. A vida dos cidadãos transcorre no espaço-tempo que marca as atividades desenvolvidas ao longo das 24 horas do dia, e essa organização tem dois âmbitos de referência fundamentais: a casa ou lar e a cidade. [...]

1 No original: “La narrativa radial evolucionó desde un imaginario de inclusión de la diferencia hasta un imaginario de diversificación de la experiencia, donde los que son diferentes ya no reivindican ser incluidos, sino reconocidos y respetados". 
As imagens e os relatos dos noticiários reproduzem basicamente um adentro e um afora que nem sempre coincidem com a separação espacial entre a morada e o exterior. 0 adentro remete ao interior da casa, mas também à intimidade, os sentimentos e os relacionamentos interpessoais, enquanto o afora geralmente está relacionado aos ruídos urbanos, o tráfego, a insegurança, a poluição, a corrupção, as autoridades, os serviços públicos e as leituras caóticas da cidade² (WINOCUR, 2002, p. 175, tradução nossa).

Mas o que acontece quando ocorre um deslocamento entre o rádio e sua audiência, quando o ouvinte deixa de estar fisicamente inserido no espaço urbano da emissora, em que partilhava imaginários, sistemas de crenças e valores? Em que medida o rádio desempenha os papéis habituais de informar, entreter e oferecer uma narrativa-mundo que confira sentido à vida cotidiana quando não se está mais na cidade?

O presente artigo busca analisar justamente como ocorre essa relação de ressignificação identitária do brasileiro que vive em Barcelona por meio do consumo do rádio expandido. A escolha da cidade catalã, onde a primeira autora teve a oportunidade de realizar estágio doutoral (sanduíche), com apoio da Coordenação de Aperfeiçoamento de Pessoal de Nivel Superior (Capes), se deve ao número significativo de brasileiros que vivem lá: 13.572 (de um universo total de 18.917 em toda a Catalunha), segundo dados de 2018 do Institut d'Estadística de Catalunya ${ }^{3}$.

Esses são apenas números oficiais. Estimativas do Ministério das Relações Exteriores apontam para um contingente muito maior de brasileiros vivendo na Espanha. Segundo o consulado em Barcelona, essa população já chegava a 37.691, quase metade do total de brasileiros no país, conforme os últimos dados disponiveis, referentes a 20154. A comunidade brasileira na Espanha (86.691) seria a sexta maior no mundo, atrás apenas de EUA (1.410.000), Paraguai (332.042), Japão (170.229), Reino Unido (120.000) e Portugal (116.271), considerando uma população de mais de 3 milhões de brasileiros vivendo no exterior, incluindo aqueles em situação irregular.

O rádio expandido (KISCHINHEVSKY, 2017) torna-se chave de compreensão das relações afetivas e identitárias que mobilizam essa audiência em condição de diáspora. Transbordando das ondas hertzianas para suportes digitais e novos dispositivos, como o telefone móvel e os smart speakers, o meio perde sua característica local, predominante desde a popularização do transístor e a ocupação da Frequência Modulada, que proporcionaram a individualização da escuta, mas reduziram seu alcance geográfico. 0 rádio em plataformas digitais agora é transfronteiriço. O brasileiro no exterior pode não apenas sintonizar em emissoras AM/FM nacionais via internet, diretamente através de seus websites ou por meio de agregadores, mas também ouvir serviços de rádio social, como Spotify, Deezer e Amazon Music, podcasts, rádios corporativas e customizadas, aplicativos de áudio georreferenciado - uma oferta significativamente maior que a dos tempos das transmissões via ondas curtas. Essa expansão do rádio o torna mais acessível, em suas múltiplas formas, bem como permite uma diversidade de modos de vinculação e de acesso, não apenas tecnológico, mas também afetivo e mnemônico.

2 No original: "Las recetas, los mitos, las creencias, los lugares comunes, el lenguaje coloquial, son parte de una estructura narrativa que puede asimilarse a la vida cotidiana, tanto en la organización del tiempo como del espacio. La vida de los ciudadanos transcurre en el espacio-tiempo que marca las actividades desarrolladas a lo largo de las 24 horas de un día, y esta organización tiene dos ámbitos de referencia fundamentales: la casahogar y la ciudad. [...]

Las imágenes y los relatos de los noticieros básicamente reproducen un adentro y un afuera que no siempre coinciden con la separación espacial entre la vivienda y el exterior. El adentro remite al interior de la vivienda, pero también a la intimidad, los sentimientos, y las relaciones interpersonales, mientras el afuera por lo general se relaciona con los ruidos urbanos, el tráfico, la inseguridad, la contaminación, la corrupción, las autoridades, los servicios públicos y las lecturas caóticas de la ciudad".

3 Disponivel em: <https://www.idescat.cat/poblacioestrangera/?geo=cat\&nac=d342\&b=2>. Acesso em: 30 jan.2020.

4 Disponivel em: <http://www.brasileirosnomundo.itamaraty.gov.br/a-comunidade/estimativas-populacionais-das-comunidades/Estimativas\%20 RCN\%202015\%20-\%20Atualizado.pdf>. Acesso em: 20 fev. 2020. 
Diante desse cenário, o presente artigo visa investigar os vínculos afetivos construídos através da escuta radiofônica por brasileiros em condição de diáspora. Trata-se da sistematização dos primeiros resultados de análise realizada no material coletado pela primeira autora por meio de entrevistas semiestruturadas com brasileiros que vivem em Barcelona, no período de setembro de 2019 a fevereiro de 2020, para tese de doutoramento intitulada "Vínculos afetivos no consumo radiofônico: identidade, território e escuta diaspórica". Busca-se analisar como os entrevistados se relacionam com o país de origem por intermédio do rádio e como ressignificam e (re)constroem suas identidades.

$\mathrm{O}$ artigo foi desenvolvido em três tópicos. No primeiro, tensionam-se os conceitos de rádio expandido, identidade e territorialidade, as bases teóricas da pesquisa. No segundo, aprofunda-se a questão de identidade, trazendo para discussão o conceito de brasilidade, que foi identificado na realização empírica da pesquisa, assim como as ideias de multiterritorialidades, desterritorialização e reterritorialização. Por fim, tensionam-se as abordagens teóricas com a análise empírica, fruto da realização de 20 entrevistas semiestruturadas com imigrantes brasileiros.

Antes de avançarmos, porém, precisamos entender melhor de que modo nos relacionamos com a comunicação sonora, elemento central no processo de subjetivação, que remete ao período anterior ao nascimento.

\section{Som, imaginário, identidade: reconfigurações no contexto do rádio expandido}

Ouvir é um ato que constitui o ser humano desde o ventre materno. 0 universo "sonoro musical precede o nascimento", conforme aponta Monica Rebecca Ferrari Nunes (2004, p. 17), compõe a realidade comunicativa do indivíduo desde a fase embrionária, em que a relação com a mãe se dá por meio de sons e ritmos, que permitem ao nascituro identificar indícios afetivos. "A voz materna nina e aleita. Sua fala, atividade rítmica e melódica, soa música ao lactente, destinatário de um discurso que só compreende como som analógico, [...] já que ainda não possui e nem decodifica a linguagem articulada" (NUNES, 2004, p. 18).

A comunicação sonora, portanto, é primal. O produto sonoro radiofônico comunica ao ouvinte não apenas as informações ou a música, mas também a rememoração de uma relação com base afetiva, que o acompanha e o remete a uma forma de comunicação habitual, à qual está intimamente atrelado. Isto faz com que o rádio, para seus ouvintes, torne-se parte integrante da realidade sonora de suas casas, de sua rotina, trazendo sensações que o transportam a um outro lugar, que o façam rememorar emoções ou que sirvam como uma forma de companhia.

Expandido, o rádio se torna um meio adaptado às tecnologias digitais de informação e comunicação, sendo ressignificado constantemente pelos ouvintes, mas mantendo características que o tornam em certa medida reconhecível. Entende-se aqui o rádio como uma linguagem comunicacional de base sonora, independente de suporte ou dispositivo (FERRARETTO; KISCHINHEVSKY, 2010). Escapa-se, dessa forma, à ultrapassada discussão sobre os limites do meio radiofônico, abrangendo-se na pesquisa o consumo midiático de outras modalidades de radiofonia, como os serviços de streaming ou o podcasting.

Diante da multiplicidade de formatos, o rádio expandido se reconfigura, proporcionando novos modos de vinculação e práticas interacionais:

Conversações que se estabelecem entre os ouvintes, a partir de conteúdos difundidos pela rádio, mediadas por seus ambientes cotidianos e por sistemas de crenças e valores. Práticas interativas específicas da rádio em plataformas digitais tais como comentários, compartilhamentos, buscas, sistemas de etiquetamento (tagging) etc. Mecanismos para a participação dos ouvintes através de chamadas telefônicas, e-mails, correio de voz, microblogging, redes sociais etc. Formas híbridas de interação nas quais vários 
elementos se combinam e se sobrepõem, de modo que resultam em novas e complexas práticas que ressignificam o processo comunicacional ${ }^{5}$ (KISCHINHEVSKY, 2017, p. 47 tradução nossa).

Devido à base sonora, que propicia uma relação de intimidade não-recíproca à distância, o rádio favorece e fortalece a construção de memórias afetivas por seus ouvintes. Ao considerarmos a memória um construto não apenas individual, mas também coletivo, algo que está atrelado às vivências pessoais, mas que é reforçado ou ressignificado pela coletividade, o rádio se torna uma forma de expressão do grupo ou de alteridade, auxiliando nessas ressignificações mnemônicas. Como já percebia Maurice Halbwachs, em trabalho pioneiro:

Para confirmar ou recordar uma lembrança, as testemunhas, no sentido comum do termo, isto é, indivíduos presentes sob uma forma material e sensivel, são necessárias. Elas não seriam, todavia, suficientes. Acontece, com efeito, que uma ou várias pessoas, reunindo suas lembranças, possam descrever muito exatamente os fatos ou os objetos que vimos ao mesmo tempo que elas, e mesmo reconstituir toda a sequência de nossos atos e de nossas palavras dentro das circunstâncias definidas, sem que nos lembrássemos de tudo aquilo (HALBWACHS, 2006, p. 26).

Repensando esse papel do rádio à luz da relação com o migrante, ganha corpo a prática da escuta em busca de uma conexão em parte afetiva, em parte identitária, que remete ao fortalecimento de uma memória prévia, mas que é ressignificada com o tempo e a distância, e também aciona a formação de imaginários pelo grupo em situação de diáspora. Como destaca a pesquisadora Denise Cogo: "As mídias podem operar transnacionalmente em termos de possibilitar a construção e o compartilhamento de imaginários identitários comuns entre os imigrantes" (COGO, 2012, p. 43).

O universo simbólico da música e do rádio compõe uma paisagem sonora que modifica e/ou reforça territorialidades. Isso porque "a cultura, a paisagem, os territórios e os lugares concedem as bases para a construção musical, que, em diferentes contextos assimilou os sons presentes no espaço" (TORRES, 2011, p. 76). Assim, os sons do rádio remetem a lugares, culturas e memórias que aludem a afetos específicos que modificam o ouvinte, ou seja, "a música retrata a cultura e a memória do povo" (TORRES, 2011, p. 77). Além disso, eles transmitem valores, ideias e, por isso, "contribuem para o surgimento de multiterritorialidades" (TORRES, 2011, p. 79).

Esse imaginário construído pelo grupo diaspórico exalta aspectos culturais, muitas vezes fixados numa perspectiva tradicionalista, na qual as mudanças tendem a ser muito mais lentas e raras que no próprio país. Contudo, essa mesma relação cultural com o local de origem também é modificada pela vivência no país atual, em confronto com a realidade cultural do novo ambiente. Os atores constroem suas identidades em um processo dialógico de identificação étnica e cultural, "por meio de intercâmbios, negociações, resoluções de conflitos e de resistência aos mecanismos e exclusão sistêmica na globalização" (COGO, 2012, p. 31-32). Essas construções identitárias, contudo, ocorrem em vivências simbólicas múltiplas e são transformadas e ressignificadas constantemente.

5 No original: "Conversaciones que se establecen entre los oyentes, a partir del contenido difundido por la radio, mediadas por sus ambientes cotidianos y por sistemas de creencias y valores. Prácticas interactivas específicas de la radio en plataformas digitales, tales como comentarios, compartidos, búsquedas, sistemas de etiquetado (tagging), etc. Mecanismos para la participación de los oyentes a través de llamadas telefónicas, correos electrónicos, correos de voz, microblogging, redes sociales, etc. Formas híbridas de interacción en las que varios elementos se combinan y superponen, de modo que resultan en nuevas y complejas prácticas que rediseñan el proceso de comunicación". 
A intensificação das migrações, por exemplo, leva ao mesmo tempo a uma proliferação de microespaços de identidade, segregados/segregadores, e a um entrecruzamento de traços culturais que produzem espaços híbridos, virtuais articuladores de novas identificações territoriais. Falamos "identificações" porque se tratam muito mais de processos do que de formas bem definidas, e muito mais de identidades plurais do que de identidades singulares. Neste sentido, o território pode veicular poderes simbólicos de múltiplas faces, ora reforçando a segregação, ora viabilizando uma dinâmica de convívio ou de ativação de múltiplas identidades (HAESBAERT, 1999, p. 187).

As múltiplas identidades, portanto, são ressignificadas ou reforçadas nos espaços híbridos surgidos das multiterritorialidades, que compreendem também a desterritorialização e reterritorialização de um grupo de migrantes ou indivíduos em outro território que não o de origem (SAQUET; MONDARDO, 2008, p. 120).

Fugimos, portanto, de uma noção essencialista de identidade, estanque, vinculada a uma cultura e a um território, herança da guinada expressivista do século 18 que afirmava a originalidade dos povos e desaguaria tanto no romantismo quanto no chauvinismo (TAYLOR, 1997, p. 471). Nos últimos anos do século XX, o debate acadêmico sobre identidade ganhou força, na esteira da consolidação dos estudos culturais. Um contingente expressivo de autores se dedicou a discutir a relação entre o global e o local (BHABHA, 2003; FEATHERSTONE, 1991). Podemos situar entre eles as reflexões de Arjun Appadurai (1991), que reconhece fatores inerentes às características de circulação e "desterritorialização" do processo global, para identificar as dimensões com que procura descrever a situação contemporânea, com suas tensões entre "homogeneização" e "heterogeneidade".

Appadurai (1997) recupera a noção de "comunidades imaginadas" desenvolvida por Benedict Anderson em âmbito nacional para pensar os processos contemporâneos de diáspora, em que muitas vezes comunidades se reconstituem em outros Estados-nação, reproduzindo seus estilos de vida em ambientes os mais diversos. 0 antropólogo indiano ajuda a desconstruir as pretensões nacionalistas a um "isomorfismo", ou seja, a ideia de que uma nação é constituída por uma identidade étnica, linguística, religiosa, etc. O contraponto curioso é que, por trás da nacionalidade, não haveria nenhuma essência perdida (tribal, provincial, local), mas apenas outras identidades idealizadas, igualmente construídas no campo do imaginário, numa estratégia retórica para formular mitos fundadores das nações contemporâneas.

Renato Ortiz vai na mesma direção:

Consideremos o conceito de identidade. No início ele evoluiu em torno da ideia de nacionalidade. $O$ termo é recente, sendo cunhado no século XIX para definir a força que molda a unidade das sociedades humanas, sua essência inerente. Esta dimensão essencialista manifesta-se nas discussões sobre raça e nacionalidade [...] (ORTIZ, 2013, p. 620).

A relação de "pertencimento" a uma nação - ou a um grupo étnico, uma comunidade de gosto - é, portanto, socialmente construída e pode ser entendida também a partir das múltiplas mediações e de complexos processos de subjetivação. Em torno da "identidade nacional" brasileira dos sujeitos em condição de diáspora, articulam-se diversos mediadores, desde as esferas do poder público, do mundo do trabalho, das relações interpessoais, até o campo cultural, passando pelos meios de comunicação. Nesse contexto, o rádio expandido, multiplataforma, com oferta planetária via internet, desempenha papel que consideramos relevante investigar. 


\section{0 fortalecimento de uma brasilidade deslocada}

O conceito de identidade, como vimos, passou por diversas modificações ao longo dos anos, sendo cada vez mais entendido como algo fluido e desterritorializado - a "identidade se revela como invenção e não descoberta; é um esforço, um objetivo, uma construção" (FARIA; SOUZA, 2011, p. 37). O risco de cair em simplificações que não correspondem à realidade multifacetada dos tempos atuais torna, portanto, complexo falar de uma ideia de brasilidade, ou de uma identidade brasileira. Contudo, os resultados obtidos na etapa empírica, aqui apresentados parcialmente, evidenciam uma noção de brasilidade como constituinte de uma identidade autoatribuída pelos entrevistados.

Ao tratar da noção de brasilidade à luz da discussão sobre identidade, Ortiz a define como "uma construção simbólica que se faz em relação a um referente". Nesse sentido, "toda identidade é uma representação, e não um dado concreto que pode ser elucidado ou descoberto" (ORTIZ, 2013, p. 622).

Essa definição põe a identidade no campo dos signos, estabelecendo uma importante relação com a alteridade. O sujeito diaspórico, por viver em uma realidade onde o Eu é posto em comparação com o Outro, passa a ter uma identidade mais bem demarcada, tanto pela busca pelo reconhecível como pelas próprias exigências burocráticas, políticas e sociais do local de morada, que o fazem recordar constantemente de sua condição de estrangeiro.

O universo do consumo, nesse sentido, é uma importante fonte de afirmação e negociação de identidades culturais. O consumo "contém os signos de um imaginário coletivo internacional popular [...]. Há uma desterritorialização de determinados signos que perdem em densidade nacional sendo ressemantizados no espaço da modernidade-mundo" (ORTIZ, 2013, p. 623).

Essa relação entre local e global ocorre também de forma desterritorializada. 0 migrante carrega consigo os signos culturais que são tensionados no novo ambiente, podendo fazer com que prevaleça, em alguns momentos, um consumo simbólico que remete mais especificamente ao local de origem.

Outro aspecto que reforça esta brasilidade é a ideia da migração inserida em um sistema de redes, que são compostas por múltiplas relações, símbolos e vínculos. Essa rede, imaterial, conecta as territorialidades, mas nunca em um processo homogêneo, e sim como constituinte de elementos que se diferenciam ao longo do tempo (HAESBAERT, 2006, p. 293).

Entre os territórios de origem e de destino, há várias relações e vínculos sociais realizados pelos migrantes quando percorrem suas trajetórias e quando se reterritorializam. A construção dos territórios, na migração, passa por uma dinâmica em redes que conectam diferentes nós interligados através dos vínculos e dos contatos estabelecidos (SAQUET; MONDARDO, 2008, p. 120).

Assim sendo, a rede conecta o local de origem ao novo local de morada, trazendo referências simbólicas, comunicativas, informativas e culturais, a exemplo do rádio e da música. O território é, portanto, "construído pelo movimento dialético de territorialização-desterritorialização-reterritorialização e, ao mesmo tempo, por redes, malhas e nós que formam a base material e imaterial de cada território" (SAQUET; MONDARDO, 2008, p. 121), algo que foi também observado na análise empírica realizada com migrantes brasileiros em Barcelona, como veremos a seguir.

\section{A percepção identitária dos brasileiros que vivem em Barcelona}

A etapa empírica desta pesquisa foi desenvolvida entre setembro de 2019 e fevereiro de 2020 . Foram entrevistados 20 brasileiros que vivem em Barcelona, selecionados a partir da diversidade de perfis. A escolha considerou faixa etária, região de origem no Brasil, gênero, escolaridade e tempo em que vive na cidade, possibilitando um mapeamento de experiências diversificadas e a identificação de possíveis 
disparidades em termos de vivências e de percepções. Os resultados obtidos demonstram, no entanto, que não há grandes divergências no que se refere à identidade nacional e ao consumo midiático.

Entre os 20 entrevistados, 13 eram mulheres e sete, homens. Quanto às regiões de origem, nove dos entrevistados vieram do Sudeste brasileiro, cinco do Sul, cinco do Nordeste e um do Norte. As idades variaram entre 19 e 60 anos, mas com predominância de pessoas com idades entre 30 e 40 anos. Cotejandose os números oficiais ${ }^{6}$, os dados etários coincidem: a maioria dos imigrantes brasileiros que mora em Barcelona tem entre 30 e 44 anos de idade e é do sexo feminino.

As entrevistas foram realizadas em locais distintos, com duração entre 50 e 60 minutos. 0 roteiro de questões semiestruturadas possibilitou o maior desenvolvimento de temas que surgiram ao longo do período. As perguntas comuns a todos os entrevistados foram: Por qual motivo veio morar em Barcelona? Há quanto tempo está vivendo aqui? Como se sente vivendo aqui como um imigrante brasileiro? Quanto à mídia, o que costuma consumir? Quais rádios brasileiras escuta? Com qual frequência ouve rádio brasileira? Por que ouve rádio brasileira, mesmo vivendo aqui? Você acompanha os acontecimentos políticos, sociais e culturais do Brasil? Do que sente falta do Brasil? A sua relação com o Brasil e com os brasileiros mudou depois que se mudou para Barcelona? Como? Quais hábitos brasileiros você abandonou depois que se mudou para Barcelona? Qual é sua concepção de imigrante? Sente que se insere nela? Busca matar a saudade do Brasil? Como?

Ressalta-se que os dados aqui sistematizados ainda são preliminares e serão devidamente desenvolvidos, trabalhados e acrescidos a outros para a elaboração da tese. Entre os resultados parciais já obtidos, destacam-se os seguintes aspectos que dizem respeito às características dos territórios étnicos e identitários formados pelos brasileiros em Barcelona: as diferentes perspectivas sobre ser imigrante; o trabalho como demarcador de alteridade; a saudade como impulsionador do vínculo radiofônico; o orgulho como busca do identificador nacional; a música como gerador de vínculos e de ressignificação geográfica favorecendo a imigração.

O primeiro aspecto observado é que não há entre os entrevistados consenso sobre o que é ser um imigrante. Porém, algo que se destaca nas falas é o viés negativo atribuído ao termo.

A confusão quanto à conceituação da imigração encontra eco inclusive na academia, que registra diferentes definições. Mesmo havendo uma concepção clara do significado de diáspora, como conceito que serve para "traduzir a realidade social, cultural e política de qualquer pessoa ou população étnica que abandona a pátria tradicional da sua etnia, estando dispersa por outras partes do mundo" (ELHAJJ; MALERBA, 2016, p. 114), as especificidades referentes ao tempo mínimo de saída do país de origem para ser considerado migrante diferem de autor para autor.

Além disso, entre alguns entrevistados o entendimento em relação ao significado de migrante era tão negativo que esses buscavam se afastar da definição, afirmando que o termo não os contemplava. A fala de um dos entrevistados resume:

Imigrante para mim é alguém que vem de forma ilegal, que se submete a trabalhar em coisas ilegais. Eu entendo que imigrante está vinculado à ilegalidade, porque se as pessoas estão aqui, ou elas foram contratadas por alguém para trabalhar ou vieram legalmente e estão aqui trabalhando [...]. Acho até chato falar do assunto imigrante ou tachar alguém como imigrante (Entrevistado II, 2019).

A concepção de imigrante como ilegal é justificada não apenas por uma noção errônea do termo, mas também pela forma como o migrante é representado. Em pesquisa realizada por Roberta Rangel Batista e Mariana Bonomo (2017) sobre as representações sociais de imigração e imigrantes nas mídias espanhola, 
italiana e portuguesa, destacou-se que os eixos mais difundidos pelo jornal El Mundo, da Espanha, são os problemas trazidos pela imigração massiva, drogas, criminalidade e ilegalidade, percepções que fortalecem uma ótica negativa do sujeito em condição de diáspora.

Entre os entrevistados, observa-se também uma clara hierarquização dos tipos de migrantes. Se a saída do Brasil teve motivos econômicos, então há uma depreciação de seu status. Se a motivação envolve conhecer novos lugares, novas culturas, mas tendo sempre a possibilidade de voltar a uma vida confortável no Brasil, os entrevistados se veem numa condição diferenciada:

\begin{abstract}
Então para mim a imigração em massa é aquela econômica, né? É um imigrante que sai do seu local de origem procurando uma vida melhor e ele faz isso com a ideia de voltar [...]. Então, claramente, eu não acho que tô nisso, eu quis (morar fora do país) [...]. É uma questão de querer sentir novas sensações, de conhecer novos lugares, de compreender uma língua nova (Entrevistado VI, 2019).
\end{abstract}

Por mais que exista esse entendimento negativo sobre a condição do migrante, muitos entrevistados admitiram não apenas sua condição diaspórica, como a permanência dessa condição em terras estrangeiras, ou seja, o entendimento de que, mesmo que vivam muitos anos em Barcelona, serão sempre brasileiros.

E por mais que você tenha 20 anos aqui, você sabe que é um imigrante. Você não se sente $100 \%$, mesmo que tenha filhos espanhóis, nascidos aqui e tudo mais, mas você ainda está nessa condição de ser imigrante e de sentir-se imigrante (Entrevistado I, 2019).

Isso evidencia mecanismos distintos de subjetivação frente a uma identificação territorial dúbia deste sujeito, inserido fisicamente em uma realidade cultural, mas ao mesmo tempo identificado com seu país de origem. Há um tensionamento na percepção que tem de si como brasileiro frente à percepção que tem de si como migrante.

o segundo aspecto observado nas entrevistas, o trabalho como evidenciação da alteridade, relaciona-se ao primeiro, mas merece destaque por considerar a ênfase que teve nas falas. Nesse tópico, evidenciam-se tanto a dificuldade em conseguir empregos nas áreas de formação, o que põe em discussão a realidade dos subempregos, como também a diferenciação entre ser imigrante e ser estrangeiro.

Dos 20 brasileiros entrevistados, sete tinham pós-graduação, e a metade deles, curso superior completo, sendo que três possuíam mais de uma formação. Apesar disso, apenas três entrevistados conseguiram trabalho em suas áreas. A dificuldade em obter emprego na área de formação é justificada tanto pelo não reconhecimento do diploma brasileiro como pela clara hierarquização que existe entre imigrantes de outros países, como o Brasil, e estrangeiros da União Europeia.

E na época da crise, em que eu cheguei, eram, clarissimamente, os trabalhos que os espanhóis não queriam. Então, 'aproveita que a hora boa é essa', 'tem que pegar estes trabalhos'. E, dentro dos imigrantes, eles também diferenciam imigrantes de estrangeiros. E tinha um currículo dizendo [...] alguma coisa de estrangeiro, e aí digo: 'pá, é pra mim'. Aí, o cara falou assim para mim: 'Não, não. Eu estou falando estrangeiro europeu'. Aí eu digo, 'pô', só faltou o cara dizer que tinha que ter olhos azuis e ser loiro. Porque ele estava me mostrando a diferença entre vir do Norte e vir do Sul, era puramente pela aparência, pelo fenótipo (Entrevistado III, 2019).

Curiosamente, a relação com o trabalho, apesar de complexa, não é hierarquizada da mesma forma que os motivos que impulsionam a imigração, talvez pelo fato de que a maioria dos entrevistados se encontrasse em condições profissionais similares. 0 trabalho é descrito pelos participantes da pesquisa como uma atividade remunerada que possibilita não apenas a permanência em Barcelona, mas também as viagens e momentos de lazer. Os entrevistados enfatizaram ainda que os salários recebidos nesses subempregos eram superiores aos que ganhavam no Brasil, em suas respectivas áreas de formação, o 
que justifica não apenas a manutenção dessas vagas, como também a minimização da própria realidade do subemprego. Mas alguns expressaram vontade de trabalhar na área de formação, manifestando certa frustração:

Agora que eu ia tentar trabalhar mesmo na minha profissão, como jornalista, como fotógrafa, como correspondente... Vai continuar na gavetinha o sonho, porque não tem mais isso [...]. Trabalhei de garçonete, em eventos, também aguentando muita humilhação, muita coisa (Entrevistada VIII, 2019).

A relação trabalhista envolvendo os sujeitos em condição diaspórica é pautada por uma série de fatores, que podem determinar a qualidade da experiência do migrante. "Ela pode ser vivenciada de forma traumática ou harmoniosa, positiva ou negativa, dependendo dos recursos do indivíduo e das características da sociedade receptora" (EBERHARDT; MIRANDA, 2017, p. 305). Ainda assim, mesmo as entrevistadas que conseguiram empregos nas áreas de formação descrevem que são continuamente lembradas de sua condição de migrante.

Faz dois anos que eu trabalho para a mesma empresa, inclusive, não foi difícil na realidade, porque os trabalhos que eu faço aqui são coisas que no Brasil eu já fazia, tirando de letra. Porque eu trabalho aqui com turismo, eu sou formada em Turismo, bacharel e tal, então eu já tinha praticamente todas as bases do Brasil. Então, aqui para mim não foi uma coisa impossivel. Mas eu sempre percebo minha condição de imigrante (Entrevistada V, 2019).

Para Georg Simmel, que construiu as bases da microssociologia no início do século XX, momento de grandes migrações, o estrangeiro usualmente se conecta "de forma abstrata e geral" a outra cultura, "não havendo assim laços de pertença" (SIMMEL, 2005, p. 269). Essa vivência do imigrante, dessa relação que nunca é totalmente confortável, que está inserida em um tensionamento constante entre ser e estar, entre o Eu e o Outro, sanciona o terceiro aspecto observado nas entrevistas, o da saudade como impulsionador do vínculo radiofônico.

A saudade foi um dos afetos mais destacados pelos entrevistados para justificar o consumo de produtos radiofônicos brasileiros. A saudade abrange diversos aspectos da vida cotidiana, como a ausência dos familiares e amigos que ficaram no Brasil, os lugares que os migrantes gostariam de frequentar novamente, a comida, a forma de agir dos brasileiros:

O que eu gosto muito do Brasil é esse improviso, de uma certa forma. 'Vamos fazer um churrasco amanhã?', 'Vamos!'! Sabe? 'Estou aqui perto da sua casa, posso passar aí?, 'Pode vir'. Não tem, aqui é muito... 'Vamos fazer um churrasco?', 'Vamos, quando?', 'Daqui a duas semanas'. Então, tipo, tem que pensar, tem que estruturar. [...] Então eu acho que essa diferença de caráter e tranquilidade brasileira é uma das coisas que eu talvez sinta falta aqui, de ser mais espontâneo (Entrevistado IV, 2019).

O rádio expandido, nesse sentido, cumpre um papel central para o sujeito diaspórico, ao oferecer uma janela sonora de acesso à língua materna, ao sotaque da região de origem, à música que acolhe e desperta memórias afetivas. Como assinala José Eugenio de Oliveira Menezes, o "cultivo da experiência do ouvir - cultura do ouvir - pode ajudar no trânsito entre as diferentes formas de abstração que conhecemos com o desenvolvimento dos aparatos ou ferramentas de comunicação" (MENEZES, 2008, p. 113)7. Graças a essas abstrações, se "desenvolvem os sentimentos de segurança e pertencimento" (MENEZES, 2008, p. 112)

7 Ouvir e escutar têm naturezas distintas, que são abordadas de formas divergentes por pesquisadores como Arnheim, Barthes, Chion, Kerckhove e Schaeffer. Para uns, ouvir é o ato de captar sons através dos ouvidos, enquanto escutar pressupõe uma ação intencional. Para outros, ambos são etapas de um processo mais amplo de audição, que culmina na percepção sonora. Para um aprofundamento dessa discussão, que foge ao escopo deste artigo, cf. Kaseker (2012, p. 29-42) e Fernández (2012, p. 74-80), entre outros. 
no ato do ouvir. Sentimentos que são muito caros ao sujeito diaspórico, que busca no rádio o acolhimento sonoro daquilo que é reconhecível.

Quando eu escuto rádio brasileira o que eu busco é Brasil, eu quero Brasil. o que significa querer Brasil? Todas as dimensões subjetivas e objetivas de querer Brasil. [...] Então, eu quero escutar, eu preciso saber o que está acontecendo em relação ao Brasil. Então, eu me informo muito, é verdade, porque politicamente eu quero estar informado e os programas informativos me informam muito. E eu quero também matar a saudade. 0 resumo é esse, eu quero matar a saudade do Brasil e eu mato muito a saudade do Brasil. [...] mas depois dá mais saudade e você escuta mais de novo e vai, um processo cíclico (Entrevistado IV, 2019).

A saudade, portanto, evidencia o aspecto afetivo relacionado ao ato do ouvir. A busca pela voz amiga do rádio é ressignificada pelo sujeito diaspórico, no sentido de que o que se busca é o reconhecimento do Eu como parte constitutiva de um lugar, de um grupo. O rádio reafirma os códigos sociais presentes na expressividade e, simultaneamente, reforça a vinculação a uma determinada gramática, uma meta-narrativa que nos posiciona no mundo.

Essa busca pelo Brasil por meio do rádio, descrita pelo entrevistado, é de um Brasil que é evidenciado de diversas formas. Passa pela inflexão da voz dos locutores, o sotaque, os usos da língua, os temas abordados, os enquadramentos. 0 vínculo sonoro se estabelece tanto quando o comentarista informa sobre assuntos políticos ou econômicos, contextualizando-os, quanto naqueles momentos em que o comunicador verbaliza uma gíria ou se expressa de modo peculiar, característico da cidade em que o migrante nasceu e viveu. Por isso, a voz no rádio permanece sendo essencial.

Aqui, às vezes eu escuto a rádio da universidade em que eu me formei. Eu tenho amigos que trabalham nessa rádio, (gosto de) ouvir a voz deles. Então, eu acho que é uma coisa de relembrar as minhas referências. Eu sou desse lugar, eu posso estar morando em Barcelona, posso estar morando na Austrália, mas eu sou desse lugar aí, sabe? Então, eu preciso saber o que está acontecendo e preciso me sentir um pouco ali também, porque me faz falta (Entrevistada X, 2019).

A voz do comunicador radiofônico personifica o interlocutor e sensibiliza o ouvinte, não apenas pelo aspecto emocional, mas também pela identificação proporcionada pelo discurso. Tal identificação não está relacionada unicamente ao teor da fala, mas também à estrutura discursiva, à linguagem, à entonação, à relação que o ouvinte cria com essa voz, às vezes não apenas reconhecível, mas amiga.

o orgulho como busca do identificador nacional também se destacou na fala dos entrevistados quando se referiam à cultura e à música brasileira. Ao serem perguntados sobre o motivo de consumirem músicas brasileiras em outro país, as respostas associavam o orgulho à qualidade da produção musical em solo brasileiro e ao prazer que tinham em dividi-las com os espanhóis e europeus, em geral:

Acho que brasileiro, todo mundo, é embaixador de certa forma. A gente sempre quer vender o Brasil. Quando vem o gringo, a gente não gosta quando as pessoas... Entre nós, falamos mal do Brasil pra caramba, mas quando tem um gringo que fala, a gente se ofende, sabe? A gente tem uma coisa de querer vender o melhor do Brasil (Entrevistada IX, 2019).

Essa troca de aspectos culturais, geradora de orgulho, produz tensionamentos quanto às expressões simbólicas que derivam do Brasil com as que são produzidas localmente. Isso ocorre tanto pela inserção da cultura do país de origem no novo local de morada, como também pela apropriação da cultura local pelo sujeito diaspórico, "selecionando, modificando e recombinando, desarticulando certos signos e rearticulando de outra forma seus significados simbólicos" (MENESES; RODRIGUES; VALE, 2015, p. 170). Essa hibridação cultural, na realidade do migrante, está relacionada a uma ressignificação dos códigos culturais, algo que gera estranhamento aos locais e aos concidadãos. 
O orgulho na troca cultural se atrela também ao reconhecimento de aspectos que compõem a identidade brasileira desses sujeitos, a valoração positiva de algo que remete a uma brasilidade, mesmo quando há a rejeição da condição de migrante. Há, nesse movimento, uma troca que aproxima os sujeitos e diminui as diferenças, dando aos brasileiros essa sensação de pertencimento mesmo em terra estrangeira.

Conforme destaca Sousa (2020, p. 34), sentimento de pertencimento se

[...] traduz de forma visivel em sentidos e motivações diversos dos de suas raízes, sustentando a busca de participação em grupos, tribos e comunidades que possibilitem enraizamento e gerem identidade e referência social, ainda que em territórios tão diferentes.

A busca pelas referências de brasilidade é impulsionada por essa necessidade de pertencer a algo que constitui sua concepção de si, mesmo em uma realidade de diversidade étnica e cultural, como é o caso de Barcelona.

E essa relação é justificada, segundo Sousa (2020, p. 45), pelo fato de que a própria "diversidade, como marca da contemporaneidade e, ao mesmo tempo, a busca de sua superação geram o que motiva o movimento de enraizamento-desenraizamento que sustenta a necessidade de pertencimento na contemporaneidade". O sentido de pertencimento é algo que permeia as ações de consumo mapeadas na pesquisa, a exemplo da escuta de emissoras brasileiras de rádio.

O tópico da música como gerador de vínculos, outro fator de destaque nas entrevistas, também se relaciona, portanto, à busca desse pertencimento. Porém, diferentemente dos outros modos de conexão, a música demonstrou ser mais efetiva ao fortalecer uma identidade brasileira e acionar afetos e memórias. Todos os 20 entrevistados confirmaram ouvir música brasileira com frequência e muitos, quando questionados sobre os motivos que os levam a escutá-la regularmente, afirmaram que a música remete a algo que os define, seja o país de origem, a língua materna ou as memórias de vida.

Para mim, a música brasileira é a minha base, é onde eu recarrego as baterias para seguir lutando. Porque existe um choque cultural, né?, não tem como você negar, a forma como eles se comportam, a forma social, o consumo da cultura deles (Entrevistada VIII, 2019).

Ainda que a hibridação cultural seja comum na realidade sociocultural contemporânea, a relação da música com o fortalecimento de uma identidade nacional não deve ser menosprezada, visto que, "na arte, se o processo de desterritorialização existe e ganha amplos espaços, também há fortes movimentos de reterritorializar, afirmando o local, o específico" (NERCOLINI, 2006, p. 126). Há, nesta desterritorialização do migrante, uma busca por reterritorialização, por meio de ferramentas culturais como a música.

O conceito de território remete a uma gama de significados que podem trazer diferentes perspectivas de análise para a relação descrita, referindo-se tanto a uma divisão geográfica, uma localidade ou região, como a territórios "subjetivos, imaginários e existenciais, produzidos a partir dos processos e dispositivos de enunciação da identidade coletiva do grupo ou comunidade" (ELHAJJ;; MALERBA, 2016, p. 114). É a noção de territórios étnicos identitários (ELHAJJI, 2011) que nos interessa aqui. Essa reterritorialização se alicerça num campo simbólico, de construção coletiva, que insere o sujeito diaspórico em uma realidade reconhecível simbolicamente, porém, desterritorializada.

A relação local e global compreende o último tópico de destaque levantado nas entrevistas, o da ressignificação geográfica favorecendo a imigração. Acontecimentos contemporâneos contribuem para essa ressignificação, destacando-se a convergência midiática, com o surgimento de tecnologias de informação e comunicação que promovem uma desterritorialização. Esse movimento é percebido, inclusive, pelos entrevistados, que citam haver nessas tecnologias uma facilitação no contato intercontinental, que diminui a distância e traz a sensação de proximidade, apesar da enorme distância geográfica: 
Eu acho muito bom por um lado, porque não dá tempo de sentir saudades das pessoas, eu tô sempre em contato com as pessoas. Então, sendo bem objetiva, pra mim não faz muita diferença eu estar em Barcelona ou em Porto Alegre, porque eu não estava morando com minha mãe, então eu não via minha mãe todo dia e falava com ela por chamada de vídeo. A única diferença é que eu vou demorar um pouquinho mais pra ver ela agora do que eu demorava pra ver antes. Mas a relação com as pessoas que estão longe é basicamente a mesma, não importa onde tu esteja, porque tu está ali, falando todo o tempo (Entrevistada XI, 2019).

Essas facilidades tecnológicas intensificam ainda mais a hibridação cultural, na medida em que a permanência simbólica do sujeito se dá em múltiplos espaços. Há, no consumo desse indivíduo, a incidência de diversas forças culturais, advindas de diferentes Estados-nação, mas que vão sendo inseridas em uma mesma realidade geográfica.

Além disso, as mídias sociais permitem o agrupamento e organização desses sujeitos, criando espaços virtuais que servem não apenas aos migrantes que vivem no país, mas aos que expressam vontade de seguir caminho similar. Essa relação é evidenciada pela busca por informações, por sanar dúvidas sobre trabalho, moradia e pela própria compreensão do que é ser um migrante no local em que vivem. Tais discussões ocorrem em grupos de WhatsApp e Facebook, como "Brasileiros em Barcelona", que servem como espaço de troca por meio de códigos sociais comuns a todos os participantes. As dúvidas, medos e críticas são compartilhadas com base em compreensões socioculturais de origem, mas confrontadas com a realidade cultural local.

Essa desterritorialização acentuada pelas tecnologias da comunicação, portanto, permite ao migrante estar em múltiplos lugares, o que justifica a perspectiva transitória descrita por alguns entrevistados, para quem estar em Barcelona é condição momentânea. A possibilidade de voltar para casa implica a manutenção da relação com o país de origem, que permanece sendo o local para o qual retornar, mesmo que essa seja apenas uma alternativa dentre muitas outras.

\section{Considerações finais}

A despeito da grande diversidade de perfis de entrevistados, foram identificadas similaridades nas experiências quanto à ressignificação identitária e à relação afetiva com o Brasil através do rádio expandido. O fortalecimento de uma ideia de identidade nacional, entre os sujeitos em condição de diáspora, se destaca. Os entrevistados se reconhecem como brasileiros e narram a busca crescente por aspectos culturais de seus locais de origem.

A brasilidade construída e ansiada abrange a valoração do rádio brasileiro, da música e de aspectos culturais que os entrevistados buscam não apenas consumir, mas também trocar com o ambiente e as pessoas com quem convivem, criando comunidades identitárias que fortalecem o sentimento de pertencimento que lhes é tão caro.

\footnotetext{
O rádio medeia a relação entre o brasileiro e o seu país de origem, aproximando os espaços distantes geograficamente e permitindo uma ressignificação do novo ambiente. A importância do meio se dá pelo fato de poder atuar "como mediação fundamental tanto na construção como na caracterização do pertencimento como linguagem de busca de identidade no contexto de um ausente comum aglutinador" (SOUSA, 2010, p. 34).
}

A conexão por intermédio do rádio permite ao migrante acessos afetivos a sua origem, os quais são mediados tanto pela música como pelos debates, informações e entrevistas que compõem a programação radiofônica, e se fazem presentes também nos formatos de podcasting. Cada um desses formatos afeta o ouvinte de forma diferente, suscitando tanto sentimentos positivos, como alegria ou acolhimento, quanto 
negativos, como revolta e tristeza. Porém, todos conectam o migrante ao seu país de origem, aproximando-o dos acontecimentos e de todo um contexto cultural.

Para o migrante, o rádio se torna um meio de vínculo com o país de origem, uma forma de se conectar com esse lugar que já não faz parte do cenário diário, com uma língua que já não é entendida por todos à sua volta e com o sentimento de pertencimento que, por vezes, é posto em questão. Ao ouvir esse rádio deslocado, opera-se em uma dupla lógica: o sujeito se reconhece como parte do local de origem representado na narrativa radiofônica e, ao mesmo tempo, afirma sua alteridade na adaptação a um novo lugar. Cria-se, assim, um microuniverso identitário dentro da realidade sociocultural macro na qual se está inserido.

o rádio, portanto, conecta o migrante a bens simbólicos que the são caros, como a língua pátria, a cultura, o sotaque, memórias afetivas. O sujeito diaspórico enfrenta uma condição de transição que o insere em uma realidade na qual ele quase nunca é plenamente reconhecido como pertencente: está sempre nessa condição diaspórica, um entre-lugar que, em geral, não havia ocupado em seu território de origem. Dia a dia, busca manter vínculos com a terra natal. Assim, a manutenção dos laços identitários por intermédio do rádio é uma forma encontrada por esses sujeitos de se reconhecerem como pertencentes a um lugar e a uma cultura, afirmando sua brasilidade, ainda que socialmente construída, por meio de contraste, de contraposição frente a um Outro idealizado (e não raro invejado).

Esses são apenas resultados preliminares da pesquisa. Espera-se aprofundar as reflexões por meio de uma segunda etapa de análise das entrevistas realizadas, cruzando as informações de escuta com as condições de oferta do ecossistema midiático catalão, possibilitando, assim, um maior entendimento da cultura do ouvinte brasileiro em condição de diáspora. 


\section{Referências}

ADORNO, Theodor W.; HORKHEIMER, Max. Dialética do esclarecimento. Trad. Guido de Almeida. Rio de Janeiro: Jorge Zahar, 1985.

ANDERSON, Benedict. Imagined communities. Londres: Verso, 1983.

APPADURAI, Arjun. Soberania sem territorialidade: notas para uma geografia pós-nacional. Novos Estudos, n. 49, nov. 1997.

Disjuncture and difference in the global culture economy. In: FEATHERSTONE, Mike (Org.). Global

culture: Nationalism, globalization and modernity. Londres: Sage, 1991.

ARNHEIM, Rudolf. Estética radiofônica. Barcelona: Editorial Gustavo Gili, 1980.

BATISTA, Roberta Rangel; BONOMO, Mariana. Representações sociais de imigração e imigrantes em mídia espanhola, italiana e portuguesa. Quaderns de Psicologia, Barcelona, v. 19, n. 3, p. 211-227, 2017.

BHABHA, Homi K. O local da cultura. Belo Horizonte: Ed. UFMG, 2003.

BIANCO, Nelia R. Del; ESCH, Carlos Eduardo; MOREIRA, Sonia Virginia. Mudanças e permanências na radiodifusão pública da América Latina. Revista Latinoamericana de Ciencias de la Comunicación, v. 12, p. 30-42, 2015.

CEBRIÁN HERREROS, Mariano. La radio en Internet: de la ciberradio a las redes sociales y la radio móvil. Buenos Aires: La Crujía, 2008.

CHARAUDEAU, Patrick. Problemas de análises das mídias. In: MEDITSCH, Eduardo (Org.). Teorias do rádio textos e contextos. Florianópolis: Insular, 2005. Volume 1.

COGO, Denise. Latino-americanos em diáspora: uso de mídias e cidadania das migrações transnacionais. Rio de Janeiro: Tríbia, 2012.

EBERHARDT, Leonardo Dresch; MIRANDA, Ary Carvalho de. Saúde, trabalho e imigração: revisão da literatura científica latino-americana. Saúde em Debate, Rio de Janeiro, v. 41, n. Especial, p. 299-312, jun. 2017.

ELHAJJI, Mohammed. Mapas subjetivos de um mundo em movimento: migrações, mídia étnica e identidades transnacionais. Revista Eptic On-Line, vol. XIII, n. 2, 2011.

. ; MALERBA, João Paulo. Dos usos comunitários da webradiofonia no contexto migratório transnacional. REMHU - Rev. Interdiscip. Mobil. Hum., Brasília, Ano XXIV, n. 46, p. 109-127, 2016. 
FARIA, Ederson; SOUZA, Vera Lúcia Trevisan. Sobre o conceito de identidade: apropriações em estudos sobre formação de professores. Revista da Associação Brasileira de Psicologia Escolar e Educacional, São Paulo, v. 15, n. 1, p. 35-42, 2011.

FERNÁNDEZ, José Luis. La captura de la audiencia radiofónica. Buenos Aires: Liber Editores, 2012.

. (Dir.). La construcción de lo radiofónico. Buenos Aires: La Crujía, 2008.

FERRARETTO, Luiz Artur. Rádio - O veículo, a história e a técnica. 3. ed. Porto Alegre: Doravante, 2007.

; KISCHINHEVSKY, Marcelo. Rádio (verbete). In: MELO, José Marques de (Org.). Enciclopédia Intercom

de Comunicação - Dicionário Brasileiro do Conhecimento Comunicacional. São Paulo: Sociedade Brasileira de Estudos Interdisciplinares da Comunicação, 2020. p. 1009-1010. Volume 1.

HALBWACHS, Maurice. A memória coletiva. Centauro: São Paulo, 2006.

HAYE, Ricardo. Sobre o discurso radiofônico. In: MEDITSCH, Eduardo (Org.). Teorias do rádio - textos e contextos. Florianópolis: Insular, 2005. Volume 1.

KASEKER, Mônica Panis. Modos de ouvir: a escuta do rádio ao longo de três gerações. Curitiba: Champagnat/ Editora PUCPR, 2012.

KISCHINHEVSKY, Marcelo. Radio y medios sociales: mediaciones e interacciones radiofónicas digitales. Barcelona: UOC, 2017.

MENEZES, José Eugenio de Oliveira. Cultura do ouvir: os vínculos sonoros na contemporaneidade. Líbero, São Paulo, ano XI, n. 21, jun, 2008.

KLÖCKNER, Luciano. Nova retórica e rádio informativo: estudo das programações das emissoras TSFPortugal e CBN-Brasil. Porto Alegre: Evangraf, 2011.

LOPEZ, Debora Cristina. Radiojornalismo hipermidiático: tendências e perspectivas do jornalismo de rádio all news brasileiro em um contexto de convergência tecnológica. Covilhã: LabcomBooks, 2010.

MORAGAS SPA, Miguel de. Perspectiva semiótica da comunicação radiofónica. In:MEDITSCH, Eduardo; ZUCULOTO, Valci (Orgs.). Teorias do rádio - textos e contextos. Florianópolis: Insular, 2008. Volume 2.

MEDITSCH, Eduardo. 0 rádio na era da informação: Teoria e técnica do novo radiojornalismo. Florianópolis: Insular, 2001.

MENESES, Antonio; RODRIGUES, Francilene; VALE, Ana Lia. Trocas e intercâmbios culturais: uma abordagem etnográfica das festas de forró e reggae na transfronteira Brasil (Bonfim)/Guiana (Lethem). Revista Territórios \& Fronteiras, Cuiabá, vol. 8, n. 2, p. 154-169, 2015. 
NERCOLINI, Marildo. A Música Popular Brasileira repensa identidade e nação. Revista Famecos, v. 13, n. 31, p. 125, 2006.

NUNES, Mônica Rebecca Ferrari. O Mito no Rádio: a voz e os signos de renovação periódica. São Paulo: Annablume, 2004.

ORTIZ, Renato. Imagens do Brasil. Revista Sociedade e Estado. São Paulo, v. 28, n. 3, p. 609-633, set./dez. 2013.

SAQUET, Marcos Aurelio; MONDARDO, Marcos Leandro. A construção de territórios na migração por meio de redes de relações sociais. Revista Nera, Presidente Prudente, ano 11, n. 13, p. 118-127, 2008.

SOUSA, Mauro Wilton de. O pertencimento ao comum mediático: a identidade em tempos de transição. Significação: Revista de Cultura Audiovisual, v. 37, n. 34, p. 31, 2010.

SIMMEL, Georg. 0 Estrangeiro. RBSE, v. 4, n. 12, p. 265-271, 2005.

TAYLOR, Charles. As fontes do self: A construção da identidade moderna. São Paulo: Edições Loyola, 1997.

TORRES, Marcos Alberto. Tambores, rádios e vídeoclipes: sobre paisagens sonoras, territórios e multiterritorialidades. GeoTextos, v.7, n.2, p. 69-83, dez. 2011.

WINOCUR, Rosalía. Ciudadanos mediáticos: La construcción de lo público en la radio. Barcelona: Gedisa, 2002. 


\section{Informações para textos em coautoria}

\section{Concepção e desenho do estudo}

Marcelo Kischinhevsky, Bárbara Maia e Belén Monclús

Aquisição, análise ou interpretação dos dados

Bárbara Maia

\section{Redação do manuscrito}

Bárbara Maia e Marcelo Kischinhevsky

\section{Revisão crítica do conteúdo intelectual}

Marcelo Kischinhevsky e Belén Monclús

\section{Informações sobre 0 artigo}

\section{Resultado de projeto de pesquisa, de dissertação, tese}

O artigo é resultado da pesquisa realizada para a tese de doutorado com tema "Vínculos afetivos no consumo radiofônico: identidade, território e escuta diaspórica", da doutoranda Bárbara Maia, orientada pelo professor Marcelo Kischinhevsky, e com etapa empírica realizada em Barcelona, durante doutorado sanduíche, com orientação da professora Belén Monclús.

\section{Fontes de financiamento}

Bolsa Faperj e Bolsa Capes Print (doutorado sanduíche) - recebidos pela autora Bárbara Maia.

\section{Considerações éticas}

Não passou por Comitê de Ética, mas todos os entrevistados assinaram termos de consentimento.

\section{Declaração de conflito de interesses}

Não se aplica.

\section{Apresentação anterior}

Não se aplica.

\section{Agradecimentos/Contribuições adicionais}

Não se aplica. 